\title{
Electrophysiological Monitoring During Acoustic Neuroma and Other Posterior Fossa Surgery
}

\author{
R.D. Linden, C.H. Tator, C. Benedict, D. Charles, V. Mraz and I. Bell
}

\begin{abstract}
Techniques used to monitor the function of the seventh and eighth cranial nerves during acoustic neuroma and other posterior fossa surgery are reviewed. The auditory brainstem response (ABR), electrocochleogram (ECochG) and direct recording from the auditory nerve (CNAP) were compared. The best technique is the ECochG, although in many cases, the CNAP should be used as a back-up technique. The CNAP is especially useful for the identification of the auditory nerve. Both can provide real-time feedback on the physiological integrity of the auditory nerve. The ABR may be helpful in monitoring brainstem function. For some procedures, optimal monitoring requires the combined recording of all three techniques.

Monopolar constant-voltage intracranial stimulation of the facial nerve is helpful for the identification and preservation of the facial nerve. Audio monitoring of spontaneous electromyographic activity provides real-time feedback on the effect of surgical manipulation of the nerve. Monitoring of ephaptic transmission in the facial nerve during microvascular decompression for hemifacial spasm aids in the identification of the offending vessel.
\end{abstract}

RÉSUMÉ: Surveillance électrophysiologique pendant la chirurgie du neurinome acoustique et autres interventions au niveau de la fosse postérieure. Nous revoyons les techniques utilisées pour surveiller la fonction du septième et du huitième nerf crânien pendant la chirurgie du neurinome acoustique et autres interventions au niveau de la fosse postérieure. Nous avons comparé les potentiels évoqués auditifs (PEA), l'électrocochléogramme (ECochG) et l'enregistrement direct à partir du nerf auditif (CNAP). La meilleure technique est l'ECochG, bien que dans plusieurs cas, le CNAP devrait être utilisé comme technique d'appoint. Le CNAP est particulièrement utile pour identifier le nerf auditif. Les deux techniques peuvent fournir une information momentanée sur l'intégrité du nerf auditif. Les PEA peuvent être utiles à la surveillance des fonctions du tronc cérébral. Pour certaines interventions on doit utiliser l'enregistrement combiné de ces trois techniques pour une surveillance optimale. La stimulation intracrânienne du nerf facial par électrode monopolaire à voltage constant est utile pour identifier et préserver le nerf facial. La surveillance acoustique de l'activité électromyographique spontanée fournit une information momentanée sur l'effet de la manipulation chirurgicale du nerf. La surveillance de la transmission éphaptique dans le nerf facial pendant la décompression microvasculaire pour le spasme hémifacial aide à l'identification du vaisseau en cause.

Can. J. Neurol. Sci. 1988; 15:73.81

One of the principal objectives of posterior fossa surgery is to preserve the function of the seventh (facial) and eighth (auditory) cranial nerves and the brainstem. Intraoperative monitoring can provide real-time feedback to the surgeon on the physiological integrity of these structures, and can reduce the risk of iatrogenic injury. The auditory brainstem response (ABR) was the first technique used to monitor the physiological integrity of the auditory nerve during acoustic neuroma surgery. ${ }^{1}$ This technique is non-invasive and easy to use. The early peaks of the ABR are relatively insensitive to the effect of anesthetics. ${ }^{2}$ However, the first peak of the ABR may be difficult to identify in the recorded waveform, especially in patients with hearing loss, and therefore, it has been recommended that a more direct method of monitoring peripheral auditory nerve function be utilized. ${ }^{3}$ This is of particular importance for intraoperative monitoring. Moller and Jannetta ${ }^{4}$ developed a method for recording the compound action potentials directly from the cochlear nerve (CNAP), which provides a large, easy to elicit response. The disadvantage with this technique is that the presence of the electrode in the operative field may be cumbersome. The electrocochleogram (ECochG) ${ }^{5,6}$ which is recorded from an electrode placed in the middle ear avoids this problem. We have examined the relative merits of these three recording techniques (ABR, CNAP and ECochG) for the intraoperative

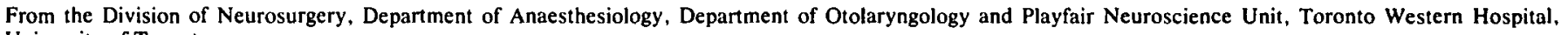
University of Toronto

Reprint requests to: Dr. R.D. Linden, Room 12-423, Playfair Neuroscience Unit, Toronto Westem Hospital, 399 Bathurst Street, Toronto, Ontario, Canada M5S 2S8 
recording of auditory and brainstem function during posterior fossa surgery.

During surgery for lesions of the cerebellopontine angle, there is also a risk of injury to the facial nerve. Electrophysiological monitoring has increased the ability of the surgeon to preserve the facial nerve. Rand and Kurze ${ }^{7}$ stimulated the facial nerve intracranially and observed facial movements. This method of monitoring is cumbersome and may require the presence of an assistant under the drapes. Furthermore, the stimulating current might spread to either the spinal accessory or trigeminal nerves, and give false-negative results. For this reason, Delgado and his colleagues ${ }^{8}$ introduced intraoperative monitoring of the electromyogram (EMG). Intraoperative photographs were taken of the EMG response from the oscilloscope to determine if there was a change in the latency or amplitude of the response. Although this method permitted identification and mapping of the facial nerve, the stimulus artifact could obscure the waveforms. To overcome this, Sugita and Kobayashi ${ }^{9}$ developed a technique for continuous monitoring of mechanical stimulation of the facial nerve by attaching accelerometers to the orbicularis oculi and oris muscles. Facial muscle movement was then converted to sound through an amplifier and speaker connected to the accelerometer. This system permitted easy identification of the facial nerve and, more importantly, also enabled the surgeon to monitor mechanical movement of the nerve, therefore providing real-time feedback indicating mechanical injury to the nerve during dissection. Moller and Jannetta ${ }^{10}$ provided the next refinement by developing a system combining sound monitoring of spontaneous EMG activity, and monitoring of EMG activity in response to direct intracranial stimulation of the facial nerve. This was accomplished by introducing a gating circuit to remove the stimulus artifact thereby allowing facial muscle action potentials to be monitored with a loudspeaker. The present report also contains our experience with the intraoperative monitoring of facial nerve function during posterior fossa surgery.
Electrophysiological monitoring of the facial nerve has also become an important intraoperative tool for microvascular decompression of the facial nerve for hemifacial spasm. " Once the facial nerve is decompressed in these patients, the ephaptic transmission disappears, and therefore this method permits the easy identification of the offending vessel, and improves the effectiveness of the procedure. This report also contains a description of our experience in monitoring facial nerve function during microvascular decompression for hemifacial spasm.

\section{Materials AND MethodS}

\section{Clinical Material}

Electrophysiological monitoring was performed on 19 patients undergoing microsurgery for the removal of acoustic neuromas or other cerebellopontine angle (CPA) tumors, or for microvascular decompression of the VII cranial nerve for hemifacial spasm (Table 1). The management of these patients, including the surgical approaches used for the removal of acoustic neuromas and other CPA tumors, have been described elsewhere. ${ }^{12.13}$ Microvascular decompression for hemifacial spasm was performed using a posterior fossa approach.

\section{Anesthesia}

Electrophysiological monitoring of auditory function during posterior fossa surgery has few anesthetic limitations. Body temperature must be monitored because hypothermia will cause an increase in the latency of the ABR responses. ${ }^{14}$ Barbiturates, inhalation anesthetics, and muscle relaxants have a small but definite effect upon the ABR. The early peaks of the ABR are much less affected than the later peaks. In our unit, anesthesia is maintained with isoflurane and nitrous oxide, and fentanyl is administered as required. Manninen et al ${ }^{15}$ examined the effect of isoflurane on the ABR and found that all the ABR peaks were affected, although the more central the generator sites of these

\section{Table 1}

\begin{tabular}{|c|c|c|c|c|c|c|c|}
\hline Patient & Procedure & ABR & ECochG & CNAP & $\begin{array}{c}\text { Facial Nerve } \\
\text { Monitoring } \\
\end{array}$ & $\begin{array}{c}\text { Auditory Nerve } \\
\text { Preservation }\end{array}$ & $\begin{array}{l}\text { Facial Nerve } \\
\text { Preservation }\end{array}$ \\
\hline 1 & APF & $*$ & $*$ & $*$ & $*$ & No & No \\
\hline 2 & ATA & & & & $*$ & No & Yes \\
\hline 3 & ATA & & & & $*$ & No & No \\
\hline 4 & CPA & & & & $*$ & No & No \\
\hline 5 & ATA & & & & $*$ & No & Yes \\
\hline 6 & CPA & & & & $*$ & No & Yes \\
\hline 7 & APF & $*$ & & & * & Yes & Yes \\
\hline 8 & ATA & & & & $*$ & No & Yes \\
\hline 9 & ATA & $*$ & & & & No & No \\
\hline 10 & CPA & $*$ & $*$ & * & $*$ & Yes & Yes \\
\hline 11 & APF & $*$ & $*$ & & $*$ & Yes & Yes \\
\hline 12 & APF & $*$ & $*$ & & $*$ & No & Yes \\
\hline 13 & APF & $*$ & $*$ & $*$ & $*$ & No & Yes \\
\hline 14 & ATA & & & & $*$ & No & Yes \\
\hline 15 & APF & $*$ & & & $*$ & No & Yes \\
\hline 16 & ATA & & & & $*$ & No & No \\
\hline 17 & APF & $*$ & & & $*$ & No & Yes \\
\hline 18 & FD & $*$ & & & $*$ & Yes & Yes \\
\hline 19 & APF & $*$ & & & $*$ & Yes & Yes \\
\hline
\end{tabular}

ATA Translabyrinthine approach for the removal of large acoustic neuromas (greater than $2 \mathrm{~cm}$ )

APF Posterior fossa approach for the removal of small acoustic neuromas (less than $2 \mathrm{~cm}$ )

CPA Other cerebellopontine angle tumours

FD Facial nerve decompression

Test performed 
components, the greater the effect. Our regimen avoids the administration of long-lasting muscle relaxants and thus allows the facial EMG to be recorded. Short-acting muscle relaxants (e.g. Atracurium) are used for induction, the effects of which have disappeared by the time the recording of the EMG activity is required. After the tumor has been removed, or the facial nerve decompressed, longer acting muscle relaxants may be given.

\section{Monitoring of Auditory Functions}

The Cadwell 8400 system was used for monitoring auditory function as described in (a), (b) and (c) below.

\section{(a) Auditory Brainstem Response}

The ABR was recorded preoperatively, intraoperatively and postoperatively. Preoperatively and postoperatively, $70 \mathrm{~dB} \mathrm{nHL}$ rarefaction clicks ( $100 \mathrm{usec}$ ) were presented through a moulded ear insert at a repetition rate of $11.1 / \mathrm{s}$ and $44.4 / \mathrm{s}$. A plastic tube, $1.9 \mathrm{~mm}$ in diameter and approximately $32 \mathrm{~cm}$ in length, was used to conduct sound from the speaker to the earmould. Response threshold was determined by presenting 50,30, and $10 \mathrm{~dB} \mathrm{nHL}$ clicks at a repetition rate of $44.4 / \mathrm{s}$. Each trial consisted of recording the averaged response to 2000 stimuli presented monaurally, and then the trial was replicated. Masking noise was presented to the ear contralateral to the stimulus at an intensity $40 \mathrm{~dB}$ less than the intensity of the click stimulus. Gold-plated cup electrodes were attached to the scalp with saline gel and collodion-impregnated gauze, and placed at $\mathrm{Cz}$, M1, M2, the Inion and $2 \mathrm{~cm}$ above each auricle (A). Four channels of activity were recorded with the following derivation: Cz-M1, Cz-M2, Cz-Inion, Cz-Ai (i = ipsilateral). A ground electrode was taped to the shoulder. The interelectrode impedences were less than $5 \mathrm{KOhms.}$

Negativity at the vertex was plotted in the upward direction. The EEG was amplified with a bandpass of 100 to $3000 \mathrm{~Hz}$. The sweep time was $10 \mathrm{~ms}$. If there was no reproducible response, the sweep time was altered to $20 \mathrm{~ms}$. Intraoperatively, $70 \mathrm{~dB}$ $\mathrm{nHL}$ stimuli were presented at a rate of $44.4 / \mathrm{s}$, but the other stimulus and recording parameters were identical to those used preoperatively.

\section{(b) Direct Recording of Compound Nerve Action Potentials from the Auditory Nerves}

The procedure used to record the CNAP was similar to the technique developed by Moller and Jannetta. ${ }^{4}$ A cotton wick electrode was constructed by removing the end $6 \mathrm{~mm}$ of insulation from Ag5T wire, to which cotton wool was sutured to the bent, exposed wire. The wire was then attached to insulated copper wire which was connected to the non-inverting input of the preamplifier. The reference electrode was constructed with a metal 25 gauge hypodermic needle connected to insulated copper wire, which was connected to the inverting input of the preamplifier. The needle electrode was inserted into muscle at the operative site, and the cotton-wick electrode was sutured to a Sugita retractor and held in place at the operative site.

Auditory click stimuli were presented through earmoulds, and masking noise was presented to the contralateral ear at an intensity $\mathbf{4 0} \mathrm{dB}$ less than the stimulus used to elicit a response. For monitoring purposes, 40 click stimuli were presented $(70$ $\mathrm{dB} \mathrm{nHL}$ ) at a presentation rate of $22.2 / \mathrm{s}$. The system bandpass was $10-3000 \mathrm{~Hz}$ and the sweep time was $10 \mathrm{~ms}$. A-1 ms sweep delay was used occasionally to monitor stimulus artifact. Figure 1 illustrates our method of monitoring auditory function with this technique.

\section{(c) Electrocochleogram - (ECochG)}

An electrode identical to that used to record the CNAP from the auditory nerve was used to record the ECochG except that $\mathrm{PtST}$ wire was used because it is more malleable than AgST and is easier to anchor in the external auditory meatus. A myringotomy was performed, through which the electrode was placed against the promontory, and the electrode was held in position by the moulded ear insert (Figure 2). The impedance of the transtympanic electrode was 40 to $50 \mathrm{KOhms}$. A needle EEG electrode placed on the face was used as the reference electrode. The effects of varying the stimulus intensity, polarity and presentation rate were examined, and the number of averages required to obtain a satisfactory signal-to-noise ratio, and optimal filter settings were determined.

\section{Monitoring of Facial Nerve Function}

\section{(a) Facial Monitoring During Acoustic Neuroma Surgery}

After the patient's head was secured in the head holder, a hand-held stimulator with metal probes was placed on the skin overlying the marginal mandibular branch of the facial nerve. The nerve was stimulated, a muscle twitch observed in the orbicularis oris muscle, and then two platinum needle electrodes were placed in the muscle. A second set of electrodes were placed in the orbicularis oculi muscle after localization by stimulating the zygomatic branch of the facial nerve. The electrode wires were taped to the face. Constant-current stimuli were used to localize the muscle twitch with the Cadwell-8400 signal averaging system being used for these preliminary procedures. Thereafter, the Grass-Moller NL-1 facial nerve locator and monitor were used for monitoring as described by Moller and Jannetta. ${ }^{10}$ One electrode from each muscle was inserted into the input probe of the Grass locator. The remaining electrodes were used as back-up electrodes. A ground

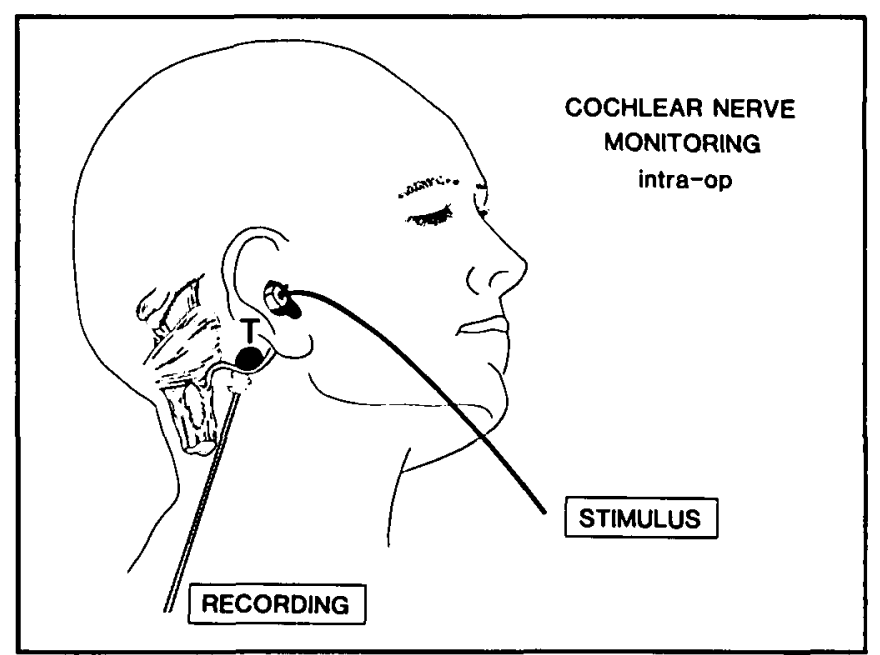

Figure l - Intraoperative monitoring of the cochlear nerve action potential (CNAP) from the eighth nerve during removal of an eighth nerve tumour (T). Auditory stimuli (STIMULUS) are delivered through an ear insert. and the response is recorded with a cotton-wick electrode placed on the exposed cochlear nerve. 


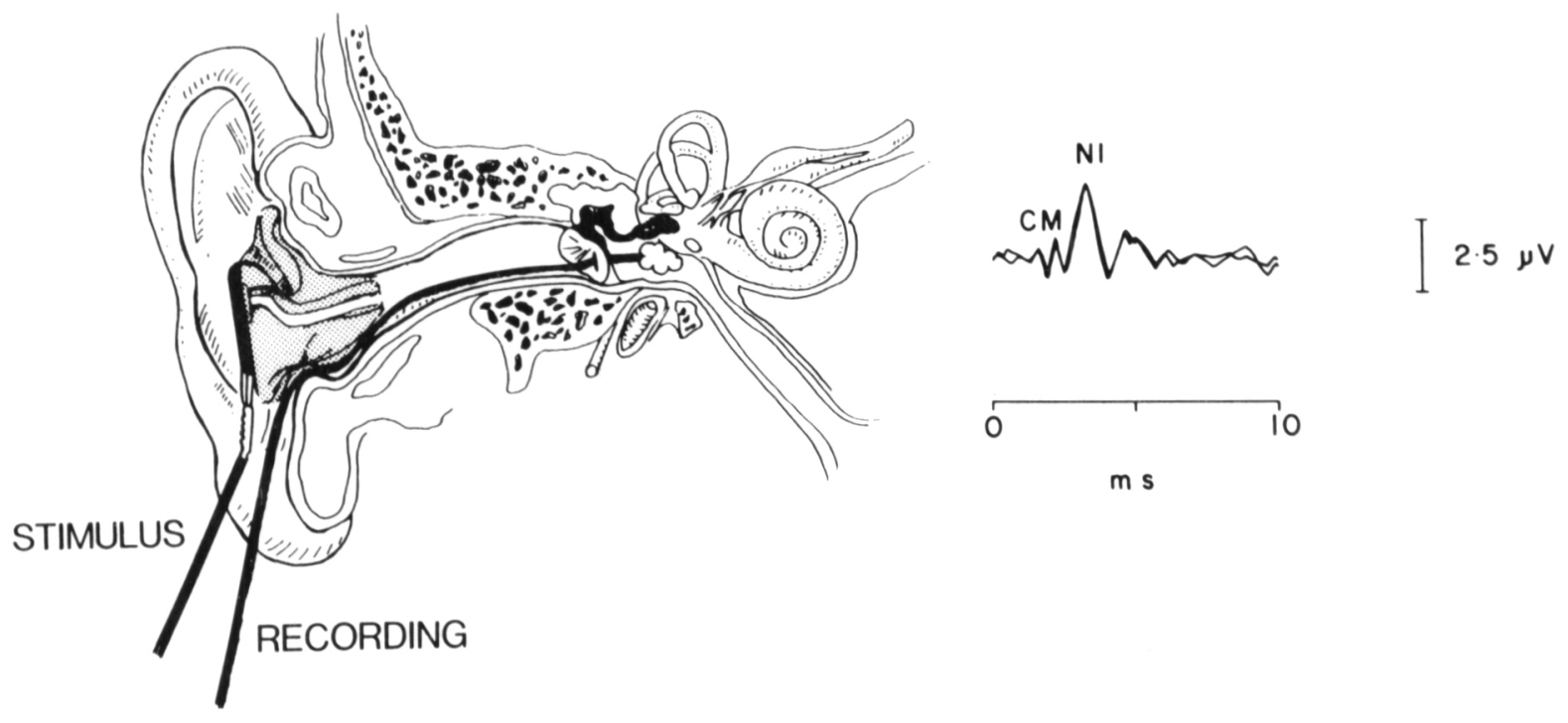

Figure 2 - Intraoperative recording of the electrocochleogram (ECochG). The schematic on the left illustrates the intraoperative technique for recording the ECochG. A cotton-wick electrode is placed transtympanically against the promontory after a myringotomy has been performed. The electrode is anchored in place with a moulded ear insert. The waveform on the right is a tracing recorded intraoperatively. Note the characteristic cochlear microphonic (CM) and compound action potential (NI) components.

electrode was placed in the forehead. The responses were differentially amplified and displayed on an oscilloscope. The system bandpass was $.3-3000 \mathrm{~Hz}$. The responses were also audio-amplified, providing immediate feedback about mechanical stimulation of the nerve. For identification purposes, monopolar constant-voltage stimulation was applied through a hand-held nerve locater unit (Figure 3). A maximum stimulus intensity of $.7 \mathrm{~V}$ was applied intracranially. Stimuli of $200 \mathrm{usec}$ duration were presented at a rate of $10 / \mathrm{s}$.

(b) Facial Nerve Monitoring During Microvascular Decompression of the Facial Nerve for Hemifacial Spasm

Needle stimulating electrodes were placed over the zygomatic and marginal mandibular branches of the facial nerve. Electromyographic activity was recorded with needle electrodes placed in orbicularis oculi and mentalis muscles. Constant-voltage stimuli (250 usec duration) were presented at a rate of $11.1 / \mathrm{s}$. The system bandpass was $1-3000 \mathrm{~Hz}$.

\section{RESULTS}

\section{(a) Auditory Nerve Monitoring}

Monitoring of the ECochG and CNAP has been of great value intraoperatively in patients with acoustic neuromas because both provide real-time feedback to the surgeon on the physiological integrity of the eighth cranial nerve. Intraoperatively, the $A B R$ has been less useful as a technique to provide immediate feedback. However, the ABR can be used as a back-up system. Furthermore, if the lesion is close to the brainstem, CNAP recordings are difficult to obtain and the ABR may then be used for monitoring. The ABR can also be used as a measure of brainstem function. For example, during the removal of a

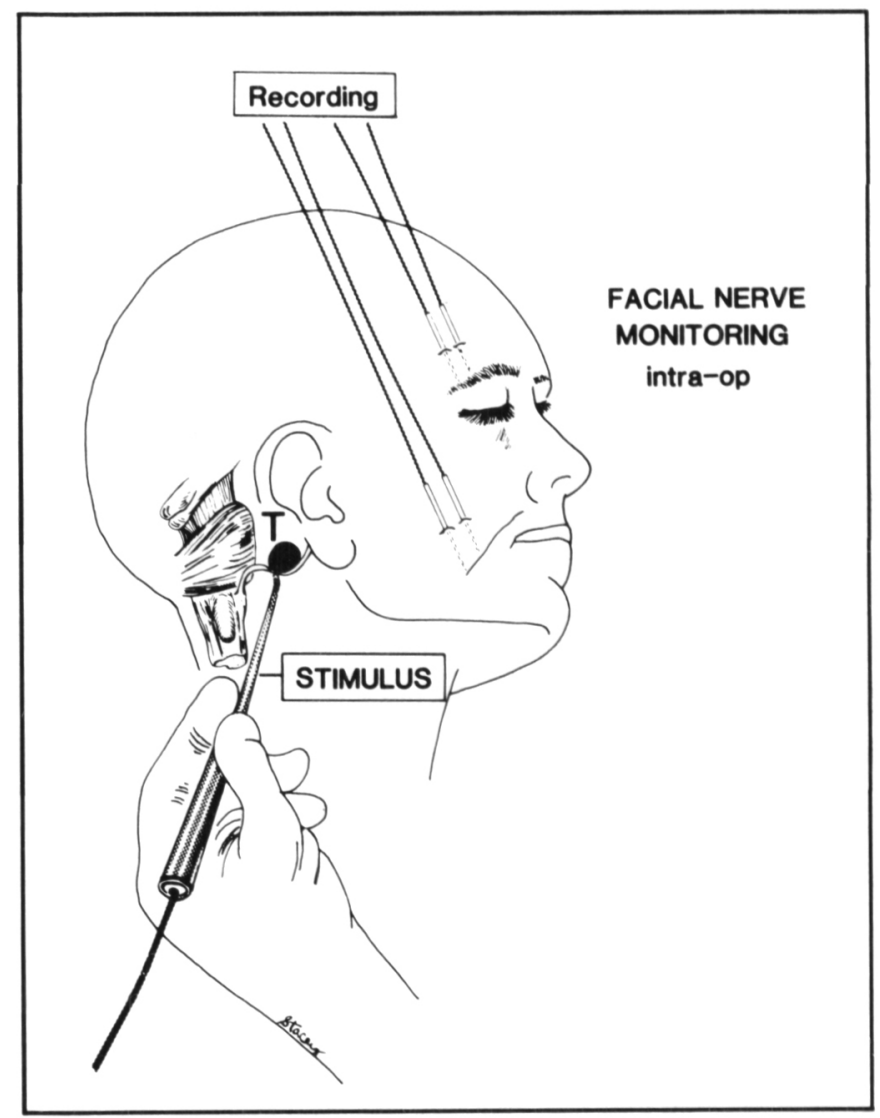

Figure 3 - Intraoperative monitoring of facial nerve function. EMG activity is recorded from the orbicularis oris (or mentalis) and orbicularis oculi muscles. A hand-held stimulator is used to identify the facial nerve displaced by a tumour (T). 
large acoustic neuroma, one patient had extensive blood loss which caused a marked decrease in amplitude and increase in latency of wave $\mathrm{V}$ of the $\mathrm{ABR}$ recorded in response to auditory stimuli delivered to the ear contralateral to the surgery. This was a helpful warning of brainstem dysfunction.

Direct recording of the CNAP from the auditory nerve was found to be very useful in many cases of acoustic neuroma in which hearing preservation was attempted. Figure 4 is from a patient with a large acoustic neuroma in whom the CNAP gradually increased in latency and decreased in amplitude, and then was lost completely. Post-operatively, hearing was absent on the operated side. One of the problems with this technique is the presence of the electrode in the operative field. The primary purpose of this method of monitoring auditory function is to identify the cochlear nerve. With this technique, the surgeon can differentiate tumor from nerve. The CNAP recording can also be used as a back-up method to other methods of continuous monitoring of auditory function.

The ECochG proved to be the best method of monitoring auditory nerve function. The cotton-wick electrode was easy to use and out of the operative field, and the recording electrode was secure when anchored in place with the ear-insert. To date, there have been no problems with the loss of the ECochG recording electrode due to displacement or high electrode impedance. However, because of these possibilities, back-up systems of monitoring such as the CNAP should be used.

The effect of stimulus polarity on the ECochG was also examined intraoperatively, and Figure 5 illustrates the importance of this relationship. Occasionally it was difficult to identify the N I component. Because the phase of the CM is opposite if condensation or rarefaction clicks are presented, the $\mathrm{CM}$ can be removed by presenting alternating stimuli. The resulting waveform clearly demonstrated the $\mathrm{N} 1$ component which represents activity generated from the auditory nerve.

The effect of stimulus intensity on the ECochG was also examined intraoperatively. When alternating clicks are presented, the cochlear microphonic (CM) is subtracted from the waveform allowing examination of the N1 component. As the stimulus intensity was increased, the amplitude of the $\mathrm{N} 1$ component increased and the latency decreased.

The effect of stimulus presentation rate on the ECochG is shown in Figure 6. The response may be recorded at high presentation rates $(88.8 / \mathrm{s})$, but as the rate of stimulus presentation was increased, the amplitude of the $\mathrm{N} I$ component decreased. However, even at fast presentation rates, a clear N1 component was evident. The CM response was also present at high presentation rates. The $\mathrm{CM}$ response was a following response. The number of cycles observed in the $\mathrm{CM}$ increased as the presentation rate increased. Because the ECochG could be recorded with a small number of averages (2-10) at a high presentation rate, real-time monitoring of the function of the auditory nerve was obtained.

The effect of altering the high-pass and low-pass filter settings was examined intraoperatively. We found that the highcut filter setting should not be lower than $3000 \mathrm{~Hz}$, and the low-cut filter setting should be $10 \mathrm{~Hz}$.

During the removal of the posterior wall of the internal auditory canal with the drill in the suboccipital approach to acoustic neuromas, it is too time consuming to pause long enough to record the $A B R$ because of the number of responses which have to be averaged. In contrast, the ECochG can be recorded

\section{CNAP MONITORING}

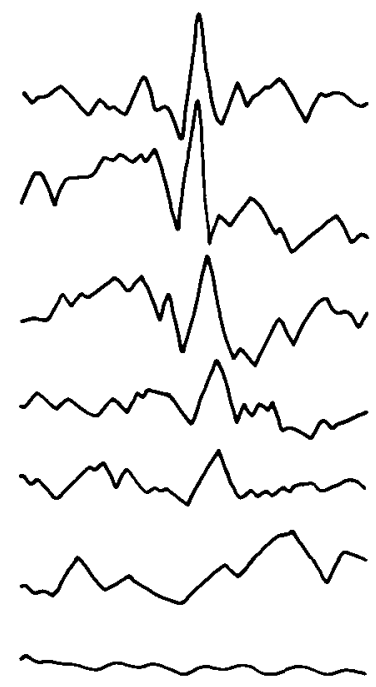

$11: 40$

12:00

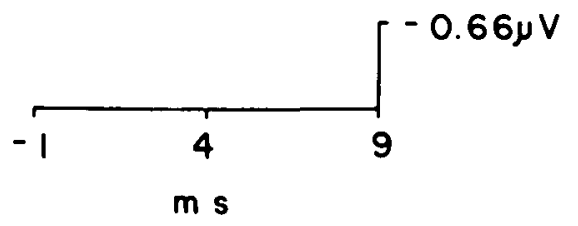

Figure 4 - Intraoperative monitoring of the compound nerve action potentials (CNAP) recorded from the auditory nerve. Hearing preservation was attempted during the removal of a large acoustic neuroma. Shown on the right of each waveform is the time of recording. At 11:40 a reproducible response was evident, but at 12:40 the amplitude of the response decreased and the latency increased. This trend continued and at 3:35 there was no response present.

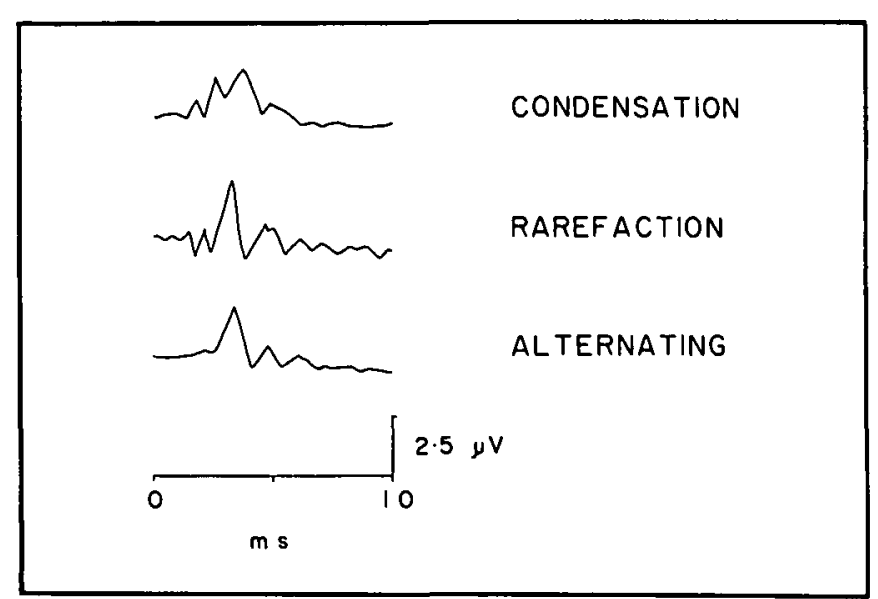

Figure 5 - The effect of stimulus polarity on the ECochG examined intraoperatively. Each waveform is the averaged response to 40 stimuli presented at a rate of $22.2 / \mathrm{s}$ at an intensity of $70 \mathrm{~dB} \mathrm{nHL}$. The tracing at the top of the figure was recorded in response to condensation clicks; the middle tracing was recorded in response to rarefaction clicks; and the lower tracing was recorded in response to alternating clicks. Note the phase reversal of the $C M$ when condensation clicks were presented as compared to rarefaction clicks. Note the removal of the CM component when alternating clicks were presented. 


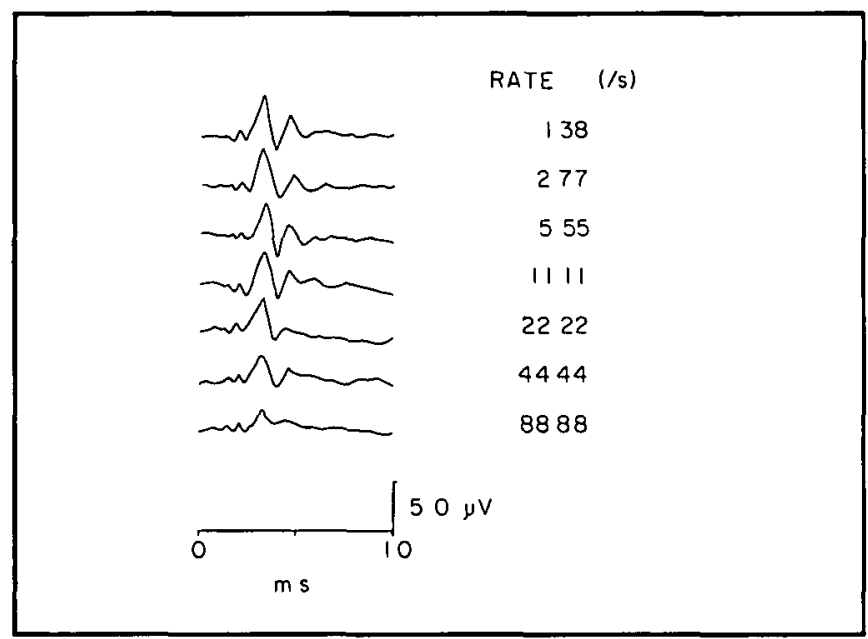

Figure 6 - The effect of stimulus presentation rate on the ECoch G recorded intraoperatively. Each represented waveform was elicited by presenting 40 rarefaction clicks at an intensity of $70 \mathrm{~dB} n \mathrm{nHL}$. The rate of stimulus presentation is listed on the right side of the figure.

in less than a second, which allows recording of the response between drilled sessions. It should be noted that waveforms should be interpreted cautiously at this time because an increase in latency and decrease in amplitude of the ECochG has been observed. This change may be caused by a temporary shift in the response threshold.

Figure 7 shows the ECochG and the CNAP from a patient with bilateral acoustic neuromas in whom hearing was preserved during the removal of a small acoustic neuroma less than $1 \mathrm{~cm}$ in diameter. During the dissection an anomalous artery entering the temporal bone was retracted and caused an abrupt loss of both the CNAP and ECochG responses. The surgeon was informed and the operation was halted. Ten minutes later, the response returned. The method of tumour removal was altered and the patient awoke with some preservation of hearing. Because of the complete yet reversible loss of the ECochG, this suggests reversible cochler ischemia.

\section{(b) Facial Nerve Monitoring}

The audio monitoring of mechanical stimulation of the facial nerve provided real-time feedback to the surgeon and was very useful during intracranial dissection of the facial nerve, especially in large acoustic neuromas. The differentially amplified EMG activity was large in amplitude and easy to record. The placement of multiple back-up electrodes in the facial muscles was helpful because the needle electrodes can dislodge. A portable impedence meter was helpful to test contiguity. In the development of our monitoring methods, a variety of hand-held facial nerve stimulators were constructed and tested. Both monopolar and bipolar constant-current and constant-voltage methods of stimulation for identifying the nerve were evaluated. The commercially available Moller stimulator from Grass Instruments proved to be the best for two reasons: the probe tip was malleable, and allowed enhanced adaptability in the operative field; and the monopolar constant-voltage stimulation provided consistent results.

Electrophysiological monitoring during microvasculardecompression for hemifacial spasm enhanced the accuracy of the procedure (Figure 8). The disappearance of the ephaptic responses was a helpful indicator of the adequacy of decompression.

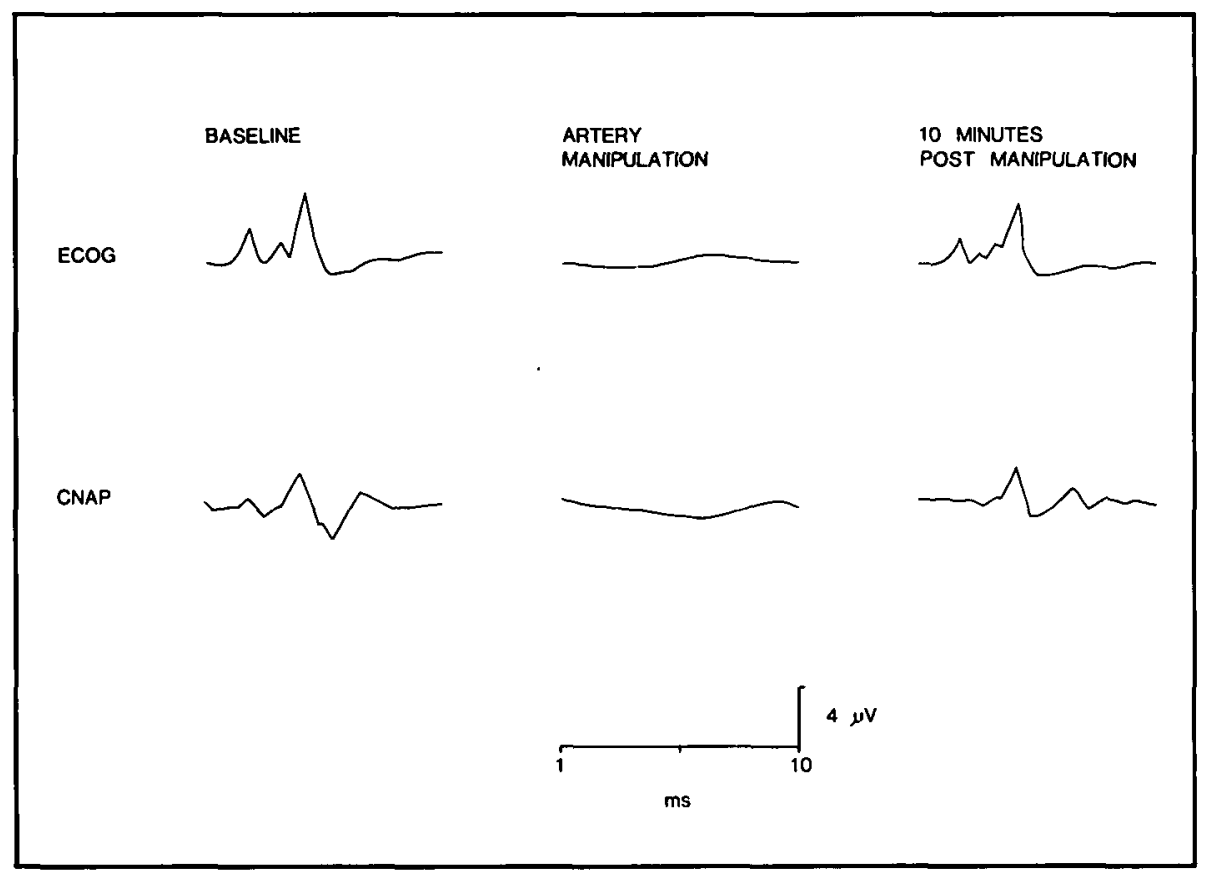

Figure 7 - The top three tracings illustrate the ECOchG recording and the lower three tracings illustrate the $C N A P$ recordings. The tracings on the left side of the figure are the baseline recordings. The tracings in the centre were recorded during the manipulation of an anomalous artery to the temporal bone when both the $E C$ Coch $G$ and CNAP readings were lost. The tracings on the right were recorded after the surgical team halted the operation for ten minutes after which the response returned. 


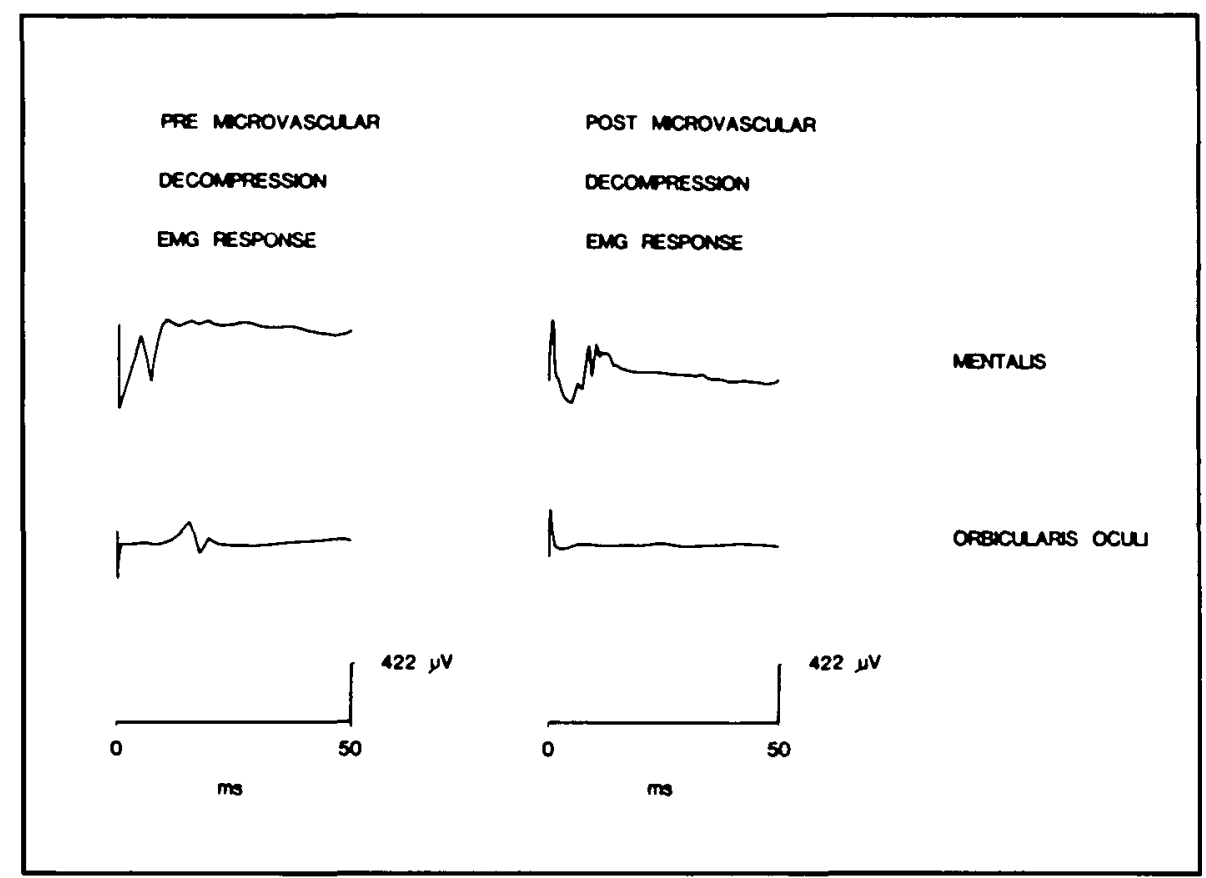

Figure 8-Electrophysiological monitoring during microvascular decompression for hemifacial spasm. The top tracings illustrate EMG activity recorded from the mentalis muscle. The lower tracings illustrate EMG activity recorded from orbicularis oculi. Both sets of tracings were recorded in response to stimulation of the marginal mandibular branch of the facial nerve. Before microvascular decompression, a direct response was recorded from the mentalis muscle and an indirect response was recorded from orbicularis oculi. After the decompression there was no longer an indirect response recordable from the orbicularis oculi muscle.

\section{Discussion}

The $A B R$ is an accurate diagnostic test in conditions such as acoustic neuroma where it is abnormal in at least $90 \%$ of cases. ${ }^{16}$ However, for a number of reasons, its value in the operating room is limited. ${ }^{6,17,18,19,20}$ Firstly, to acquire an adequate signal-to-noise ratio requires the averaging of thousands of responses, which is time consuming. Secondly, the later components of the ABR are effected by hypothermia ${ }^{14,21}$ and some anesthetics. ${ }^{15.22 .23}$ Finally, during intraoperative monitoring of the $A B R$, wave $V$ has been used to identify the response, but intraoperative changes in wave $\mathrm{V}$ do not correlate well with post-operative hearing preservation. ${ }^{6}$ Accordingly, attention has been directed towards monitoring the earlier responses of the auditory system, especially at the level of the auditory nerve because these earlier signals are more resilient to changes in body temperature ${ }^{24}$ and are less affected by anesthetic level. ${ }^{15}$

There is a wealth of literature on the clinical use of the ECochG. ${ }^{25,26,27}$ The ECochG was first recorded intraoperatively in the 1960's during middle ear surgery. ${ }^{28,29}$ Because of the work of Levine and his colleagues ${ }^{5}$ there has been a reawakening of interest in the intraoperative recording of the ECochG. The stimulus/intensity function of the $\mathrm{N} I$ component of the ECochG which we have observed intraoperatively is similar to that described by Eggermont. ${ }^{25}$ The amplitude of the $\mathrm{N}$ I component decreases and the latency increases as the stimulus intensity is decreased. At the highest intensities, corresponding to the $\mathrm{H}$ area of the amplitude/intensity function, the $\mathrm{N} /$ component may have three peaks. At lower intensities the second peak is the most prominant. ${ }^{27}$ As the stimulus rate is increased, the $\mathrm{N} 1$ response amplitude decreases and the latency increases. However, the $\mathrm{N} 1$ component is still present at fast rates $(200 / \mathrm{S}) .{ }^{30}$ When the rate is greater than $80 / \mathrm{s}$, the summating potential may contaminate the recordings. Therefore, we recommend a rate of 44/s. Until the clinical usefulness of the $\mathrm{CM}$ is determined, alternating click stimuli should be applied to remove the $C M$, which can, as we have demonstrated, contaminate the $\mathrm{N} 1$ component of the waveform.

The ECochG has several advantages, including ease of recording and the absence of the electrode in the operative field. It has also been reported that the ECochG is not altered by anesthetic levels. ${ }^{6}$ However, there are several aspects of the intraoperative recording of the ECochG which require further research. Firstly, the method of recording might be improved. For example, Stone et $\mathrm{al}^{31}$ reported that the ECochG can be recorded from a low impedance electrode placed near the opening of the external auditory canal, rather than transtympanically. Although transtympanic recordings are larger, they require penetration of the tympanic membrane. Further research is required to determine the effectiveness of the external electrode technique in the operating room. A second area requiring further research is the $\mathrm{CM}$ response, which may provide an accurate assessment of the inner hair cells of the cochlea. To date, most of the work has focused on the $\mathrm{N} 1$ component. Because of the periodicity of the CM component, frequency based techniques such as Fourier analysis may be used to analyze this response.$^{32}$ Indeed, response detection methods may be significantly improved by using optimal digital filtering ${ }^{32 a}$ and higher level statistical techniques, such as the Hotellings $t 2$ test $^{33}$ or "phase coherence" ${ }^{34}$ Finally, the effects of anesthetics and temperature on the ECochG should be more rigorously examined. 
Use of the ECochG alone has several limitations. Firstly, the recording electrode may be dislodged away from the promontory during the operation, and would be difficult to replace. Thus, whenever possible, the CNAP and the ABR should also be recorded as back-up methods. Another potential problem with the ECochG is that the N1 component is thought to be generated from the distal portion of the auditory nerve and accordingly, if the tumour is proximal to the generator site of the $\mathrm{N} \mathrm{l}$ component, the ECochG may not detect an injury to the nerve near the tumour. This problem may also be minimized by the additional recording of the CNAP and ABR.

We conclude that the peripheral auditory nervous system can be accurately monitored with the combination of the ECochG and the CNAP. With small acoustic neuromas, combined recording provides excellent monitoring for operations designed for hearing preservation (Table 1). For monitoring during the removal of large acoustic neuromas, a different approach is required because hearing preservation is no longer the primary objective of auditory evoked potential monitoring. ${ }^{12}$ With large tumours, the function of the facial nerve and the brainstem are in jeopardy and electrophysiological methods of monitoring these structures are required. The $A B R$ can be used for monitoring brainstem function, although the ABR is not sensitive to damage to areas of the brainstem other than the ascending auditory pathway. Indeed, Piatt et $\mathrm{a}^{35}$ recommended that the sensitivity of electrophysiological monitoring would be enhanced if somatosensory evoked potentials were recorded in conjunction with the ABR. Further work is required in this important area.

New surgical approaches for the removal of large acoustic neuromas have improved the likelihood of preservation of the facial nerve, ${ }^{12}$ and the same is true for electrophysiological monitoring. Electrical stimulation helps to identify the facial nerve, although there is controversy about the optimal method for intracranial stimulation of the facial nerve. Babin et $\mathrm{al}^{36}$ recommended a bipolar constant-current stimulator for localization of the facial nerve, whereas Moller et al ${ }^{10}$ preferred monopolar constant-voltage stimulation. Pras $\mathrm{s}^{37}$ described stimulation with flush-tip probes and found no advantage to either constant-current or constant-voltage stimulation. We found that the monopolar constant-voltage technique developed by Moller is reproducible, easy to use, and very helpful for preserving facial nerve function (Table 1). Moller and Jannetta ${ }^{10}$ also recommended this technique for stimulating tumour tissue prior to removal if there is doubt about the location of the facial nerve. Finally, we also recommend audio monitoring of spontaneous EMG activity because it can provide real-time feedback on the effect of surgical manipulation on the facial nerve.

Idiopathic hemifacial spasm has been attributed to compression of the root entry zone of the facial nerve by a blood vessel. $^{38,39,11}$ Intraoperatively, it is possible to determine the offending vessel electrophysiologically. The exact mechanism by which impulses are transmitted along non-stimulated branches of the facial nerve when another branch is stimulated is unknown. Moller and Jannetta ${ }^{11}$ reviewed this phenomena. Transmission is either ephaptic or through the facial motor nucleus. Wherever the abnormal activity is generated it is relieved after decompression. Although this abnormal transmission is mainly caused by compression due to blood vessels, in certain cases, other lesions of the cerebellopontine angle may be the cause of the compression ${ }^{40}$ This mode of monitoring may help to differentiate if the lesion is vascular. Because there is a risk of injury to the auditory nerve during microvascular decompression for hemifacial spasm, auditory function should also be monitored during these procedures. ${ }^{41}$

\section{ConcLusion}

Electrophysiological monitoring in the operating room is a rapidly evolving field. For each sensory modality, methods of monitoring are being developed and improved on. These techniques can enhance the safety and accuracy of many procedures. Monitoring of auditory nerve and facial nerve functions exemplifies the ability of these tools to improve both safety and accuracy during acoustic neuroma and other posterior fossa surgery.

\section{ACKOWLEDGEMENTS}

The authors would like to express their thanks to the following: Ms L. Kennedy for preoperative and postoperative audiological testing; Dr. R. Harrison for providing helpful comments on the methodology for recording the electrocochleogram; Mr. J. Loukides for building the cotton-wick electrodes; and Miss C. Dickson for secretarial assistance.

\section{REFERENCES}

1. Raudzens PA. Intraoperative monitoring of evoked potentials. Ann NY Acad Sci 1982; 388: 308-326.

2. Nuwer MR. Evoked potential monitoring in the operating room. New York: Raven Press 1986.

3. American Electroencephalographic Society. Guidelines for clinical evoked potential studies. J Clin Neurophysiol 1984; 1: 3-53.

4. Moller AR, Jannetta PJ. Compound action potentials recorded intracranially from the auditory nerve in man. Exp Neurol 1981; 74: 862-874.

5. Levine RA, Ojemann RG, Montgomery WM, et al. Monitoring auditory evoked potentials during acoustic neuroma surgery: Insights into the mechanisms of the hearing loss. Ann Otol Rhinol Laryngol 1984; 93: 116-123.

6. Ojemann RG, Levine RA, Montgomery WM, et al. Use of intraoperative auditory evoked potentials to preserve hearing in unilateral acoustic neuroma removal. J Neurosurg 1984; 61: 938-948.

7. Rand RW, Kurze TL. Facial nerve preservation by posterior fossa transmeatal microdissection in total removal of acoustic tumours. J Neurol Neurosurg Psychiatry 1965; 28: 311-316.

8. Delgado TE, Buchheit WA, Rosenholtz HR, et al. Intraoperative monitoring of facial muscle evoked responses obtained by intracranial stimulation of the facial nerve: $A$ more accurate technique for facial nerve dissection. Neurosurgery 1979; 4: 418-420.

9. Sugita K, Kobayashi, S. Technical and instrumental improvements in the surgical treatment of acoustic neurinomas. J Neurosurg 1982; 57: 747-752.

10. Moller AR, Jannetta PJ. Preservation of facial function during removal of acoustic neuromas. J Neurosurg 1984b; 61: 757-760.

11. Moller AR, Jannetta PJ. On the origin of synkinesis in hemifacial spasm: results of intracranial recordings. J Neurosurg 1984a;61: 569-576.

12. Tator $\mathrm{CH}$, Nedzelski JM. Facial nerve preservation in patients with large acoustic neuromas treated by a combined middle fossa transtentorial translabyrinthine approach. J Neurosurg 1982; 57: 1-7.

13. Tator CH, Nedzelski JM. Preservation of hearing in patients undergoing excision of acoustic neuromas and other cerebellopontine angle tumors. J Neurosurg 1985; 63: 168-174.

14. Stockard JJ, Sharbrough FW, Tinker JA. Effects of hypothermia on the human brainstem auditory response. Ann Neurol 1978; 3 : 368-370.

15. Manninen PH, Lam AM. Nicholas JF. The effects of isoflurane and isoflurante-nitrous oxide anesthesia on brainstem auditory evoked potentials in humans. Anesth Analg 1985; 64: 43-47. 
16. Hart RG, Gardner DP, Howieson J. Acoustic tumours: Atypical features and recent diagnostic tests. Neurology 1983;33:211-221.

17. Allen A, Starr A, Nudlekman K. Assessment of sensory function in the operating room utilizing cerebral evoked potentials: a study of fifty-six surgically anesthetized patients. Clin Neurosurg 1981; 28: 457-481.

18. Grundy BL, Jannetta PJ, Procopio PT, et al. Intraoperative monitoring of brainstem auditory evoked potentials. J Neurosurg 1982; 57: 674-681.

19. Raudzens PA, Shetter AG. Intraoperative monitoring of brainstem auditory evoked potentials. J Neurosurg 1982; 57: 341-348.

20. Hardy RW Jr, Kinney SE, Lueders AH, et al. Preservation of cochlear nerve function with the aid of brainstem auditory evoked potentials. Neurosurgery 1982;11: 16-19.

21. Kaga K, Takiguchi T, Mayo Kai K, et al. Effects of deep hypothermia and circulatory arrest on the auditory brainstem responses. Arch Otorhinolaryngol 1979; 225: 199-205.

22. Thomton C, Heneghan CPH, James MFM, et al. Effects of halothane or enflurane with controlled ventilation on auditory evoked potentials. Br J Anesth 1984; 56: 315-323.

23. Wilson KS, Wilson LA, Cant W. The effect of halothane upon auditory evoked potentials. In: Nodar RH, Barker C, eds. Evoked Potentials II. Butterworth: Boston 1984; 490-496.

24. Rosenblum SM, Ruth RA, Gal TJ. Brainstem auditory evoked potential monitoring during profound hypothermia and circulatory arrest. Ann Otol Rhinol Laryngol 1985; 94: 281-283.

25. Eggermont JJ. Electrocochleography. In: Keidel WD, Neff WD, eds. Handbook of Sensory Physiology. V/III New York: SpringerVerlag 1976; 625-705.

26. Gibson WPR. In: Halliday AM, ed. Evoked Potentials in Clinicial Medicine. Churchill Livingstone 1982; 283-311.

27. Gibson WPR. Essentials of clinical electric response audiometry. Churchill Livingston, Edinburgh, London and New York; 1978.

28. Ruben RJ, Bordley JE, Lieberman AT. Cochlear potentials in man. Laryngoscope 1961; 71: 1141-1164.

29. Ronis BJ. Cochlear potentials in otosclerosis. Laryngoscope 1966; 76: $212-231$.
30. Chatrian GE, Wirch AL, Lettich E, et al. Click-evoked human electrocochleogram. Noninvasive recording method, origin and physiologic significance. Am J EEG Technol 1982; 22: 151-174.

31. Stone JL, Hughes JR, Kumar A, et al. Electrocochleography reconded non-invasively from the external ear. Electroenceph Clin Neurophysiol 1986; 63: 494-496.

32. Linden RD. Human auditory steady state evoked potentials. Doctoral Dissertation University of Ottawa; 1985.

32a. Fridman J, Zappulla R, Bergelson M, et al. Application of phase spectral analysis for brainstem auditory evoked potential detection in normal subjects and patients with posterior fossa tumours. Audiology 1984; 23: 99-113.

33. Rodriguez R, Picton TW, Linden RD, et al. Human auditory steady state responses: Effects of intensity and frequency. Ear and Hearing 1986; 7: 300-313.

34. Makeig S. Studies in musical psychobiology, Doctoral Dissertation. University of California, San Diego, CA; 1985.

35. Piatt HR Jr, Radtke RA, Erwin CN. Limitations of brainstem auditory evoked potentials for intraoperative monitoring during posterior fossa operations: Case report and technical note. Neurosurgery $1985 ; 16: 818-821$.

36. Babin RW, Ryu JH, McCabe BF. Bipolar localization of the facial nerve in the internal auditory canal. In: Graham MD, House WF, eds. Disorders of the Facial Nerve. New York: Raven Press 1982; 3-5.

37. Prass, Communication in Neurosurgery; 1986.

38. Gardner WJ, Sava GA. Hemifacial spasm - a reversible pathophysiologic state. J Neurosurg 1962; 19: 240-247.

39. Janetta PJ. Microsurgical exploration and decompression of the facial nerve in hemifacial spasm. Curr Top Surg Res 1970; 2: 217-220.

40. Davis WE, Luterman BF, Pulliam MW, et al. Hemifacial spasm caused by cholesteatoma. Am J Otol 1981; 2: 272-273.

41. Moller MB, Moller AR. Loss of auditory function in microvascular decompression for hemifacial spasm. Results in 143 consecutive cases. J Neurosurg 1985; 63: 17-20. 